\title{
Regularization of peat humic acids functional composition
}

\author{
Natalia Chukhareva ${ }^{1, *}$, Oksana Zarubina ${ }^{1}$, and Alexey Zarubin ${ }^{1}$ \\ ${ }^{1}$ Tomsk Polytechnic University, School of Earth Science \& Engineering, 634050, Lenin Avenue, 30, \\ Tomsk, Russia
}

\begin{abstract}
Humic acids are perspective complicated natural objects for different purposes. The problem of humic acids functional composition regularization is very important. The effect of heat treatment on peat humic acids group composition alteration was evaluated to solve this problem. The projection study by principal component analysis of IR-spectra data is presented. The possibility of peat humic acids functional composition regularization by temperature treatment and subsequent storage was found.
\end{abstract}

\section{Introduction}

Humic acids (HA) are complex organic materials which are used for various agricultural and industrial purposes $[1,2]$. Due to their complex composition and highly-developed surface these compounds are good adsorbents [3]. It is known antibacterial and antioxidant properties of humic acids in medicine. Humic acids can be extracted from different types of natural sources such as peat. The Tomsk region (Russia) has significant natural resources of peat deposits. However, humic acids are complicated natural objects, and a problem of regularization of their physical and chemical properties is there. The study of properties and ways of extraction of peat-based materials has always been paid great attention [4-6]. Unfortunately, until now, there is no uniform approach to choice of processing materials based on peat. The main aim of this study is to verify the possibility of humic acids functional composition regularization.

\section{Objects \& Methods}

Humic acids were extracted from fen, transitional, and terrestrial peats to depth of $0.5 \mathrm{~m}$ of eleven areas in the Tomsk region (Russia) with decomposition degree (R) ranging from 25 to $45 \%$. The set of physico-chemical parameters of peats such as botanical composition, elemental composition, and group composition is presented in [7].

Extraction sequence was carried out according to [8] and included:

- bitumen extraction via benzol;

\footnotetext{
* Corresponding author: Natasha@tpu.ru
} 
- extraction of water-soluble and easy-hydrolysable substances from bitumen-free peat samples;

- extraction of HAs from bitumen-free peat samples (treatment by $0.1 \mathrm{M}$ solution $\mathrm{NaOH}$ and further precipitation of $\mathrm{HA}$ by $10 \% \mathrm{HCl}$ ).

Humic acids were subsequently heated at $250{ }^{\circ} \mathrm{C}$ in its decomposing gases according to [9] and were stored at room temperature in the closed flasks with no exposure to light for period of 24 months.

Optical properties of peat humic acids were studied by IR spectroscopy. Principle component analysis (PCA) was used for representation of humic acids by a set of properties.

IR spectra were obtained at the National Research Tomsk Polytechnic University laboratory through the application of FTIR spectrometer, Nicolet iS10 (Termo Fisher Scientific), equipped with the special attachment of frustrated total internal reflection (FTIR) with a diamond crystal. Experiment parameters were as follows: resolution $-4 \mathrm{~cm}^{-1}$, number of sample scans and comparison spectrum - 64 scans with range from 4000 to 650 $\mathrm{cm}^{-1}$. In order to obtain spectra of humic acids samples, they were crushed and sievegrinded up to $0.25 \mathrm{~mm}[7]$.

All humic acids spectra were registered and processed using "Omnic 8.3" software. Automatic baseline correction was carried out to eliminate effects caused by attenuated total reflection. This method was used to register absorption band shifts and the wavelength influence on the depth of penetration into the sample.

Principle component analysis is widely used for the investigations of multivariate data from natural objects $[10,11]$. The instrumentation of PCA allows to reduce the dimensionality of multivariate data by highlighting the principal components (PC) and interpreting the properties of investigated objects in the new dimension of PC's [12]. The implementation of PCA in an Excel spreadsheet editor is described by A.L. Pomerantsev [13].

Based on the IR data sets, the mathematical model of HAs representation was constructed.

\section{Results and discussion}

The absorption bands in IR spectra of humic acids extracted from peat extracted from peat of various botanical composition, type and degradation amount are similar and located in the stretching zone of $\mathrm{OH}$-groups $\left(3400 \mathrm{~cm}^{-1}\right)$ joined by intramolecular hydrogen bonds in alcohols and water, methylene $\mathrm{CH}_{2}$-groups and methyl $\mathrm{CH}_{3}$-groups $\left(2920 \mathrm{~cm}^{-1}\right.$ and $\left.2850 \mathrm{~cm}^{-1}\right)$, carboxyl $\mathrm{C}=\mathrm{O}$-groups $\left(1725-1700 \mathrm{~cm}^{-1}\right), \mathrm{C}=\mathrm{C}$ poly-coupling aromatic system $\left(1620-1600 \mathrm{~cm}^{-1}\right)$ and monoaromatic structures $\left(1520-1500 \mathrm{~cm}^{-1}\right)$.

Generally, after heating at $250{ }^{\circ} \mathrm{C}$ intensity of signals at $3400 \mathrm{~cm}^{-1}$ decreases due to desorption of water and oxidation of $\mathrm{OH}$-groups:

\section{$\mathrm{R}-\mathrm{OH} \stackrel{[\mathrm{O}]}{\mathrm{a}} \mathrm{R}-\mathrm{COOH}$}

After heat treatment of humic acids in the IR spectra we can trace intensity decrease in the stretching $\mathrm{CH}_{2}$ - and $\mathrm{CH}_{3}$-groups at $2920 \mathrm{~cm}^{-1}$. This fact confirms that the structures became more aromatic.

The intensity of absorption bands for the $\mathrm{C}=\mathrm{O}$ groups at $1725-1700 \mathrm{~cm}^{-1}$ and $\mathrm{CO}$ groups of acids increases. It indicates the changes in humic acids functional composition due to the interaction of thermal decomposition products (esters, aldehydes, ketones) with pyrogenetic water. This is result of the new carboxyl groups formation [7]. 
However, the general trends of temperature treatment are very clear; it is difficult to evaluate the degree of functional composition regularization. PCA analysis was used to receive information about possibility of composition unification. Such approach was applied previously in investigation of temperature influence on air-dry peat of Siberian region by a set of properties [14]. It was shown, that heating promotes to regularization of peats. Based on the IR data sets, the mathematical model of humic acids representation was constructed. The results are shown in figure 1.

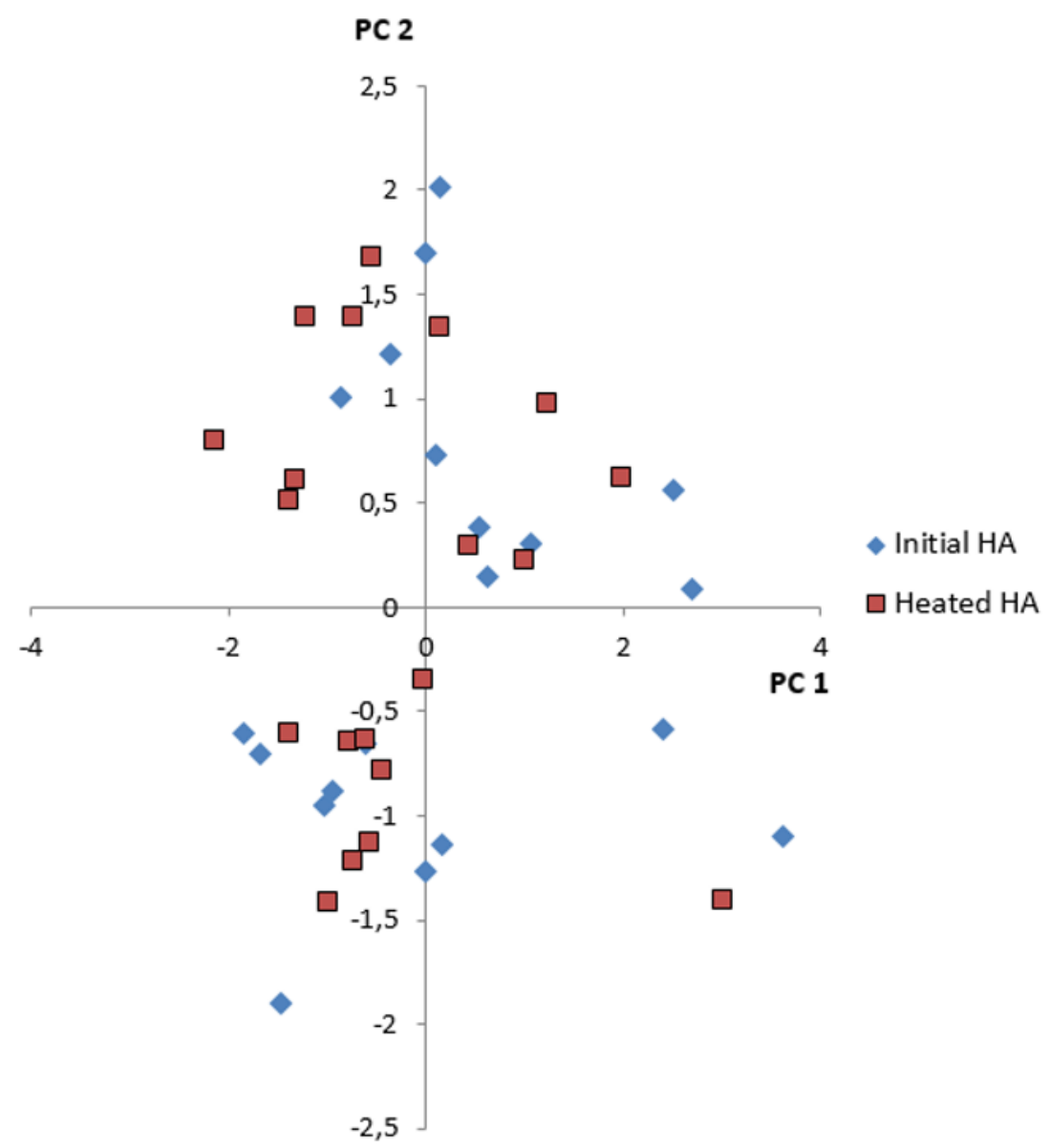

Fig. 1. Scores of first and second principle components for initial and heated humic acids.

There is no dramatic influence of temperature treatment on humic acids unification.

To evaluate the influence of storage on functional composition, IR spectra of heated humic acids samples after 24 months were registered. There are no clear trends in changes in the intensity of absorption bands. But, it was shown that the PLS-analysis results for samples became more located after 24 months of storage. The results are presented in figure 2 . 


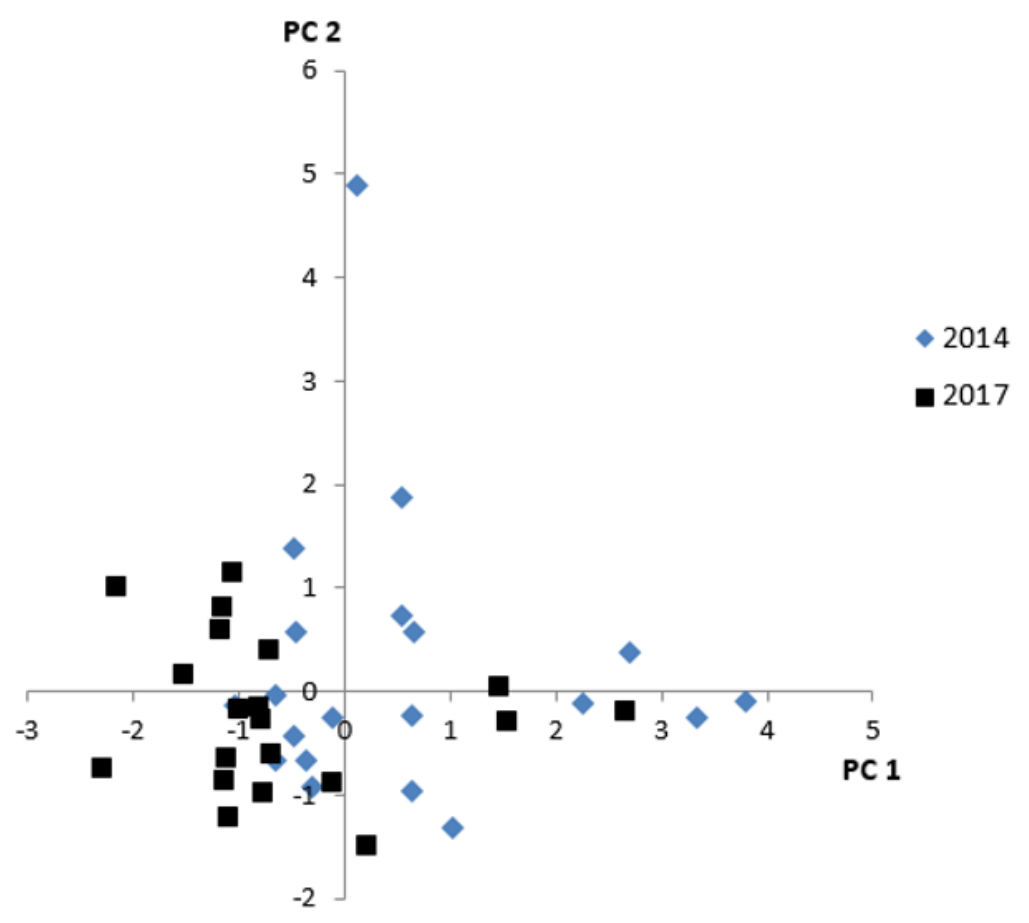

Fig. 2. Scores of first and second principle components for heated samples before and after the storage.

Generally, except of three samples of humic acids, extracted from terrestrial peat with low degree of decomposition, functional properties of humic acids became more normalized. We can not exclude that oxidation processes between residue of air in the closed flasks and HAs take place and all these processes were finished in the course of storage.

\section{Conclusion}

There is no significant difference in IR spectra of humic acids, extracted from peat of various botanical composition, type and degradation degree. The reduction of stretching intensity of $\mathrm{OH}$ groups and $\mathrm{C}-\mathrm{H}$ groups at $3400 \mathrm{~cm}^{-1}$ and $2920 \mathrm{~cm}^{-1}$ and the increase of absorption band intensity of $\mathrm{C}=\mathrm{O}$ groups at $1725-1700 \mathrm{~cm}^{-1}$ are observed after heat treatment. However, IR spectra of humic acids before and after heating at $250{ }^{\circ} \mathrm{C}$ are similar. It is difficult to make any conclusions about regularization of functional composition on the base only of IR data. The PCA shows no clear regularization of humic acids immediatly after the heat treatment. There are no clear trends in change of IR signals intensity after the storage. Generally, functional properties of heated humic acids became more normalized after the storage at room temperature in the closed flasks with no exposure to light.

\section{References}

1. G. Bremanis, M. Klavins, O. Purmalis, R. Ziemelis, S. Maïecka, Proc. Latv. Acad. Sci. Sect. B 67, 3, 684 (2013) 
2. S. Farouk, A.A. Mosa, A. A. Taha, Heba M. Ibrahim, A.M. EL-Gahmery, Journal of Stress Physiology \& Biochemistry 7, 2 (2011)

3. P. Boguta, Z. Sokołowska, PLoS ONE 11, 4 (2016)

4. I. Lishtvan, N. Korol, Science and technology 320, 12 (1975) [in Russian]

5. M. Arifur Rahman, M. Abu Hasan, A. Rahim, A.M. Shafiqul Alam, Pak. J. Anal. Environ. Chem. 11, 1 (2010)

6. K. Kujala, M. Seppälä, and T. Holappa, Physical properties of peat and palsa formation. Cold Regions Science and Technology 52, 3 (2008)

7. N. Chukhareva, T. Korotchenko, D. Rozhkova, Procedia Chem. 10 ( 2014 )

8. R.S. Swift, Organic matter characterization, Methods of soil analysis, Part 3: Chemical methods. SSSA Book, 5 (1996)

9. S.I. Smolyaninov, S.G. Maslov, Peat thermobriquetting (1975) (in Russian)

10. J. Muller, M. Kylander, A. Martinez-Cortizas, R.A.Wüst, D. Weiss, K. Blake, R. Garcia-Sanchez, Cosmochim. Acta 72, 2 (2008)

11. M. Klavins, et al. Mires \& Peat 3 (2008)

12. R. Wehrens, Chemometrics with R: multivariate data analysis in the natural sciences and life sciences Springer (2011)

13. A.L. Pomerantsev, Chemometrics in Excel John Wiley \& Sons (2014)

14. N. Chukhareva, A. Zarubin, O. Bulgakova, IOP Conf. Ser.: Earth Environ. Sci. 21 (2014) 